Nepalese Vet. J. 35:142- 149

\title{
Effect of Music on Animal Behavior: A Review
}

\author{
S. Dhungana ${ }^{1}$, D. R. Khanal ${ }^{2}$, M. Sharma ${ }^{3}$, N. Bhattarai ${ }^{1, *}$, D. T. Tamang ${ }^{1}$, S. Wasti ${ }^{3}$ \\ and R. C. Acharya ${ }^{1}$ \\ ${ }^{1}$ Agriculture and Forestry University, Chitwan, Rampur, Nepal \\ ${ }^{2}$ Animal Health Research Division, NARC, Khumaltar, Lalitpur, Nepal \\ ${ }^{3}$ University of Hawaii, Manoa, Hawaii, USA \\ *Corresponding author: nbhattarai@afu.edu.np
}

\begin{abstract}
Music is an expression of moods and emotions, which has a history of physical and emotional healings. It is thought to have both analgesic and anxiolytic properties. Various effects of music therapy on the physiology and psychology of human have been documented. The effect of music on physiology and behavior have been studied in animals too. Many of these studies claim that even animals are affected by the music. The potential benefits of music in animals might be through auditory enrichment which modifies the behavior of animals. The milking behavior and milk yield of farm animals including cattle and buffalo are affected by music. The objective of this study was to review the influence of music in animal behavior and discuss its usefulness for stress relief. The available literatures indicated that there is a variation among animals for music preference and their behavior is affected depending upon the animal species.
\end{abstract}

Keywords: Animals; Behaviour; Effect; Music

\section{INTRODUCTION}

Music is the expression of moods and emotions, which has a history of physical and emotional healings (Trehan, 2004). Any unwanted sound is noise (Broucek, 2014) and music is also a kind of sound. Whether or not a music is to be described as noise depends on the subjective notion depending upon whether hearing brings positive and negative feelings (Broucek, 2014). The effects of any kind of sound including music on animal behavior and productivity depends not only on its frequency, intensity $(\mathrm{dB})$, pattern and duration, but also on the ability of the animal species to perceive. It also depends on the sound exposure history of the animal and to the stimuli of music (Castelhano-Carlos and Baumans, 2009). Human behavior in many ways have been influenced by music depending on the genre of music where classical music is found to have soothing effect but fast rock music has exciting effect (Dalton and 
Behm, 2007). Since years, music has been successfully used to reduce the stress, depression, pain, and anxiety (McCaffrey and Good, 2000; Hilliard, 2001 and Vickers and Cassileth, 2001) as well as to improve body immunity (Gangrade, 2012 and Alsworth, 2013). This indicates that the music has both analgesic and anxiolytic properties. The music therapist usually generates music either from flute or piano or from other source that pleases the mind and can be used as an alternative form of therapy (Lipe, 1987 and Christie, 1992). The effects of music therapy on the physiology and psychology of humans have been well documented. The comparison of music to the white noise, that has been composed specifically to enhance mood in humans, found that both of them increased the rates of socialising behaviors such as play (Graves, 2011), but only the music decreased abnormal behavior (Robbins, L.,\& Margulis, S.W.; 2014).

The effect of music on physiology and behavior has been a matter of study on various animal species too. Many authors have reviewed the sensitivity of birds, baboons, monkeys, gibbons, dogs, cats and many other species to different types and levels of sound (Broucek, 2014). Auditory enrichment through music has improved the welfare of animals by masking noises and decreasing anxiety and stress (Patterson-Kane \& Farnworth, 2006). The objective of this review was to understand effects of music on different aspects of animal behaviors.

\section{MATERIALS AND METHODS}

Various literatures including journals, proceedings, research reports and master's thesis research regarding music, and animal behavior were reviewed, and inferences were drawn mainly based on the findings of the past studies carried out.

\section{RESULTS AND DISCUSSION}

\section{Effects of music in different animal species}

\section{Birds}

Head bobbing and foot lifting in response to music was found in Sulphur-crested cockatoos and African gray parrots (Patel, A. D., Iversen, J. R., 2009; Schachner, A., Brady, T. F., 2009). Young Songbirds learn how to sing properly only after hearing adult songs. Naturally, the young deaf and isolated birds develop abnormal songs (Brainard, M.S., \& Doupe, A. J., 2002; Waser, M. S., \& Marler, P., 1977). Birds have the highest increase of auditory threshold in the higher frequency ranges after exposure to sound of 95-100 decibel (dB) (Marler et al., 1973, Algers et al., 1978). Disturbance from animals or human can be avoided with background sound level of $50 \mathrm{~dB}$ (Clough, 1999). 


\section{Baboons and Gibbons}

Radio music has been found to decrease the heartrate of laboratory housed baboons (Brent and Weaver, 1996), but abnormal behavior was observed in rhesus macaques (Macaca mulatta) (O’Neill, 1989). This indicates that same music can have different effects depending upon animal species.

\section{Chimpanzees}

The use of sound system for example playing compact discs (CD) or MP3 music could increase socialization in laboratory housed chimpanzees (Howell et al., 2003). Classical instrumental music could effectively increase amicable behavior in laboratory housed chimpanzees than vocal music (Videan et al., 2007).

\section{Elephants}

Loud sound is well known for its adverse effects on heart rate and blood pressure in both humans and animals (Geverink et al., 1998; Morgan, Tromborg, 2007). Wells and Irwin, 2008 analysed valuable effect of music of classical type on stereotypy in zoo housed Asian elephants (Elephas maximus), with elephants showing less abnormal behavior on exposure to classical music.

\section{Rats}

Many studies have been performed to understand the effect of music in laboratory rats. As their usual social communication occurs in ultrasonic range (Patterson-Kane, E. G., \& Farnworth, M. J., 2006), it is difficult to believe that they enjoy music for humans (Panksepp, J., \& Bernatzky, G., 2002). Da Cruz, et al., (2011) found that exposure to chronic treatment with simvastatin (1 or $10 \mathrm{mg} / \mathrm{kg} /$ day) reduced anxiety levels in rats when Mozart music was played in an elevated plus-maze.

\section{Dog}

Kogan (2012) investigated the impact of classical, heavy metal, and specially designed or altered classical music on vocalization, activity level, and shaking of body in kenneled dogs. Vocalization and body shaking was lowered while sleep duration was increased in dogs after classical music was played in the kennel. The fast and loud music like heavy metal increased both vocalizations and body shaking.

\section{Cats}

Snowdon et al., (2015) created species-appropriate music for domestic cats and compared with music that has similar affective content composed for humans. Two examples of cat music in counterbalanced order with two examples of human music were presented, and the behavior and response latencies of cats to each piece were evaluated. It was found that cats showed a significant preference for and interest in species-appropriate music compared with the other type. 


\section{Pigs}

The researches carried out in pigs found no significant difference on the number of vocalizations between two conditions: one during playing music and another during stressful procedures in the farm (Cloutier et al., 2000).

\section{Equine}

Classical, jazz or rock music was found to have non-significantly less calming effect in ponies than country music (Houpt et al., 2000). Very few researches have been carried out on equine music preference.

\section{Cattle}

Lanier et al., 2000 found dairy breeds to be more sensitive to musical sound than beef breeds. Algers and Jensen (1991) exposed dairy cows to 80-100 dB of sound for 1.4 hour twice daily instead of their preferred musical sound. This resulted in reduced milk yield in dairy cows and even interrupted ejection in progress (Algers et al., 1978). The physiological responses of dairy cows to noise were reported by Broucek et al., (1983). Loud cry causes stress responses in farm animals (Hemsworth et al., 2003). Shouting on dairy cows appears to be very aversive (Pajor et al., 2000). Sound made by human shouting and slamming of metal gates increases heart rate and activity in cattle (Waynert et al., 1999). Abrupt high intensity sound like low altitude jet aircraft flights at milking time could stimulate increased peripheral or mammary release of catecholamines (Albright and Arave, 1997). Eexcessive sound has an influence on behaviour and coordination. This further tells that music which is also a sound also has effect depending on its intensity. Many of these studies claim that even animals cannot remain unaffected by the music. Slow music is found to increase daily milk yield in cows by $3 \%$ while $2 \%$ decrease by fast music (Nold, 2007). Wells, 2009 found classical and country music to have more positive effects on behavior than rock music increasing stress. In stress, milk cortisol concentrations increase (Gygax et al., 2006). Results from playing the classical music for an extended period of time produced a steady increase in milk production (Kenison, L., 2016).

\section{Effects of music on Buffalo}

Buffaloes behavior and their production may be affected by music. This is supported by the research carried out by S.M.M. Abuzead and A.M. Khalil, 2007 who presented slow music to buffalo cows and noticed that they spent ample time displaying behaviors like absence of rumination and standing still with great attention and directing the ears towards the source of sound indicating relaxation. The slow music 
led the buffaloes to be physically and psychologically prepared to milking spending less time showing stress behavior like increase in milk latency period than the control ones. Moreover, slow music could make nervous buffalo cows to respond and they could easily be manipulated compared to control buffalo group. Soothing noise is stimulating and relaxing which resulted in increased milk production (McCowan, et al., 2002). Higher levels of stress lead to decreases in total milk production (Hopster, 2002).

\section{CONCLUSION}

The effect of music on animals is found to be species specific varying from positive to negative or no effect. It also depends on the type of music. Music influences the animal behavior as well as helps to increase the milk yield of farm animals like buffaloes and cows. Listening of preferred music has a calming effect that reduces stress and finally improves the milk production in milk producing animals. On contrary, unpreferred music has a noising effect that increases stress and finally reduces milk yield. The auditory enrichment through music reduces the stress of the animals and helps to ensure a normal or calm behavior. Using species-appropriate music helps tolower stress in animals.

\section{ACKNOWLEDGEMENTS}

The authors would like to offer their sincere gratitude to the Department of Animal Breeding and Biotechnology, Faculty of Animal Science, Veterinary science and Fisheries, Agriculture and Forestry University; Animal Health Research Council, NARC, Khumaltar, Kathmandu and University of Hawaii, Manoa, Hawaii, USA for their valuable support during this review.

\section{REFERENCES}

Abuzead, S.M.M. and Khalil, A.M. (2007). Behavioral and Physiological Influences of Listening Slow and Fast Music on Milking Buffaloes. Assiut Vet. Med. J. Vol. 53: 114

Albright, J. L., \& Arave, C. W. (1997). The behaviour of cattle. CAB international.

Algers, B., \& Jensen, P. (1991). Teat stimulation and milk production during early lactation in sows: effects of continuous noise. Canadian Journal of Animal Science, 71(1), 51-60.

Algers, B., Ekesbo, I., \& Strömberg, S. (1978). The impact of continuous noise on animal health. Acta veterinaria Scandinavica. Supplementum, 68: 1-26. 
Algers, B.; Ekesbo, I. and Sromberg, S. (1978): The impact of continous noise on animal health. Acta Vet. Scand. 19 (suppl. 67), 1-26.

Alworth, L. C., \& Buerkle, S. C. (2013). The effects of music on animal physiology, behavior and welfare. Lab animal, 42(2): 54.

Brainard, M. S., \& Doupe, A. J. (2002). What songbirds teach us about learning. Nature, 417(6886), 351.

Brent, L., \& Weaver, O. (1996). The physiological and behavioral effects of radio music on singly housed baboons. Journal of Medical Primatology, 25(5): 370-374.

Broucek, J. (2014). Effect of noise on performance, stress, and behaviour of animals. Slovak Journal of Animal Science, 47(2): 111-123.

Castelhano-Carlos, M. J. - Baumans, V. 2009. The impact of light, noise, cage cleaning and in-house transport on welfare and stress of laboratory rats. Laboratory Animals, vol. 43, 2009, p. 311-327.

Cloutier, S., Weary, D. M., \& Fraser, D. (2000). Can ambient sound reduce distress in piglets during weaning and restraint? Journal of Applied Animal Welfare Science, 3(2): 107116.

Da Cruz, J. N., de Lima, D. D., Dal Magro, D. D., \& da Cruz, J. G. P. (2011). The power of classic music to reduce anxiety in rats treated with simvastatin. Basic and Clinical Neuroscience, 2(4): 5.

Dalton, B. H., \& Behm, D. G. (2007). Effects of noise and music on human and task performance: A systematic review. Occupational Ergonomics, 7(3): 143-152.

Graves LM. 2011. The effect of auditory enrichment on abnormal, affiliative, and aggressive behavior in laboratory housed rhesus macaques (Macaca mulatta) [Master's thesis]. San Marcos, TX: Texas State University.

Gygax, S. E., Schuyler, J.A., Kimmel, L. E., Trama, J. P., Mordechai, E., \& Adelson, M. E. (2006). Erythromycin and clindamycin resistance in group B streptococcal clinical isolates. Antimicrobial Agents and Chemotherapy, 50(5): 1875-1877.

Hopster, H. R. M. B., Bruckmaier, R. M., Van der Werf, J. T. N., Korte, S. M., Macuhova, J., Korte-Bouws, G., \& Van Reenen, C. G. (2002). Stress responses during milking; comparing conventional and automatic milking in primiparous dairy cows. Journal of Dairy Science, 85(12): 3206-3216. 
Houpt, K., Marrow, M., \& Seeliger, M. (2000). A preliminary study of the effect of music on equine behavior. Journal of Equine Veterinary Science, 20(11), 691-737.

Kenison, L. (2016). The Effects of Classical Music on Dairy Cattle (Doctoral dissertation).

Kogan, L. R., Schoenfeld-Tacher, R., \& Simon, A. A. (2012). Behavioral effects of auditory stimulation on kenneled dogs. Journal of Veterinary Behavior: Clinical Applications and Research, 7(5): 268-275.

Marler, P. (1973). A Comparison of Vocalizations of Red-tailed Monkeys and Blue Monkeys, Cercopithecus ascanius and C. mitis, in Uganda. Ethology, 33(3-4): 223-247.

McCaffrey, R. G., \& Good, M. (2000). The lived experience of listening to music while recovering from surgery. Journal of Holistic Nursing, 18(4): 378-390.

Morgan, K. N., \& Tromborg, C. T. (2007). Sources of stress in captivity. Applied Animal Behaviour Science, 102(3): 262-302.

Panksepp, J., \& Bernatzky, G. (2002). Emotional sounds and the brain: the neuro-affective foundations of musical appreciation. Behavioural Processes, 60(2): 133-155.

Patel, A. D., Iversen, J. R., Bregman, M. R., \& Schulz, I. (2009). Experimental evidence for synchronization to a musical beat in a nonhuman animal. Current biology, 19(10): 827-830.

Patterson-Kane, E. G., \& Farnworth, M. J. (2006). Noise exposure, music, and animals in the laboratory: a commentary based on Laboratory Animal Refinement and Enrichment Forum (LAREF) discussions. Journal of Applied Animal Welfare Science, 9(4): 327332.

Robbins, L., \& Margulis, S. W. (2014). The effects of auditory enrichment on gorillas. Zoo biology, 33(3): 197-203.

S.M.M. Abuzead and A.M. Khalil. (2007) Behavioral and Physiological Influences of Listening Slow and Fast Music on Milking Buffaloes. Assiut Vet. Med. J. Vol. 53:114 July 2007

Schachner, A., Brady, T. F., Pepperberg, I. M., \& Hauser, M. D. (2009). Spontaneous motor entrainment to music in multiple vocal mimicking species. Current Biology, 19(10): 831-836.

Snowdon, C. T., Teie, D., \& Savage, M. (2015). Cats prefer species-appropriate music. Applied Animal Behaviour Science, 166, 106-111. 
Trehan, S. (2004). Music to my ears. Journal of PMedicine, 7(6): 868-869.

Videan, E. N., Fritz, J., Howell, S., \& Murphy, J. (2007). Effects of two types and two genre of music on social behavior in captive chimpanzees (Pan troglodytes). Journal of the American Association for Laboratory Animal Science, 46(1): 66-70.

Waser, M. S., \& Marler, P. (1977). Song learning in Canaries. Journal of Comparative and Physiological Psychology, 91(1): 1.

Waynert, D. F., Stookey, J. M., Schwartzkopf-Genswein, K. S., Watts, J. M., \& Waltz, C. S. (1999). The response of beef cattle to noise during handling. Applied Animal Behaviour Science, 62(1): 27-42.

Wells, D. L., Coleman, D., \& Challis, M. G. (2006). A note on the effect of auditory stimulation on the behaviour and welfare of zoo-housed gorillas. Applied Animal Behaviour Science, 100(3): 327-332. 